\title{
Prediction for Damage Depth of Coal Seam Floor Based on the BP Neural Network \\ Shun-Feng $\mathrm{LI}^{1, \mathrm{a},{ }^{*}}$ \\ ${ }^{1}$ Chensilou coal mine, Henan Longyu Energy Corpration, Yongcheng, 476000, China \\ alishunfeng6666@sina.cn \\ ${ }^{*}$ corresponding author
}

Keywords: Artificial Neural Network, Floor Damage Depth, Inrush, Matlab Software, Forecasting Formula.

\begin{abstract}
On the basis summary of forecasting methods and theoretical depth of stope floor, combining a large number of actual data analysis, it is induced that the following six aspects are the main factors influencing the floor damage depth the: mining depth, dip angle of coal seam, mining thickness and length of working face, floor ability to resist damage and presence of cutting wear fault or fracture zone. Based on artificial neural network input required samples and test samples, through the Matlab software to network training, it is concluded that the optimization of the network model, and according to the established network model, Chensilou coal mine 21201, 2408 and 20301 working faces damage depth has been established. Compared with the measured results, the floor damage prediction formula of depth and deep relationship was obtained.
\end{abstract}

\section{Introduction}

The determination of coal floor damage depth is an important determinant of whether the coal floor water inrushing, therefore it has the vital significance for the coal mine under the condition of big deep coal floor damage depth prediction for confined water outburst danger degree of coal floor discriminant. At present, there are some floor damage depth of the measured gain methods, the numerical simulation method [1-2], theoretical formula method [3] and empirical formula method [4-6], etc. But these methods are single factor and model establishing relatively ideal shortcomings, the predicted results with measured results obtained are usually different [7]. So, it is a problem in the research of production safety how to predict floor damage depth from many factors level. This article is based on the BP neural network method to predict the depth of the floor damage.

\section{The Influence Factors of Damage Depth for Coal Floor}

There are many factors that can affect floor damage depth, but due to a large part of all these factors associated with noise, which directly affected the accuracy of the floor damage depth [8-9]. However the floor damage depth model based on BP neural network in the building will have to consider to reduce or eliminate the impact of these unfavorable factors. The measured data and theoretical studies have shown that [10-12], the main factors influencing the coal floor damage depth, including: the measured data and theoretical research shows that the coal floor damage depth and coal mining work face of mine pressure and coal floor damage resistance, the influence factors of concrete mainly has: the mining depth, dip angle of coal seam, mining thickness and working face length, floor ability to resist damage type and presence of cutting wear fault or fracture zone.

\section{The BP Neural Network Prediction Model}

\section{Sampling}

The depth of floor damage model based on BP neural network to build, it is completed based on considering various influencing factors of bottom damage effect at the same time, through the 
analysis of a large number of sample data processing. In the construction of the BP neural network model, using the Matlab program simulation training. In this paper, according to our country existing coal floor damage depth of the measured data, with 31 fields measured data as the training and testing samples. $1 \sim 26$ from 31 samples as the learning sample to train network, to the rest of the five instances as prediction samples for testing the performance of the network.

\section{Online Learning in Training}

The classic BP neural network has been established. Based on 8 kinds of experimental network structure as shown in table 1, respectively for training, various trials network mean square error of the mean has obtained, as shown in table 1 and table 2.

Tab. 1 Test Network Structure

\begin{tabular}{|c|c|c|c|c|c|}
\hline \multirow{2}{*}{$\begin{array}{c}\text { Test network } \\
\text { ID }\end{array}$} & \multirow{2}{*}{$\begin{array}{c}\text { the layer } \\
\text { number }\end{array}$} & hidden layer & \multicolumn{3}{|c|}{ excitation function } \\
\cline { 4 - 6 } & & number $\mathrm{n}$ & input layer & $\begin{array}{l}\text { implicit } \\
\text { strata }\end{array}$ & output layer \\
\hline 1 & 2 & 12 & Sigmoid & - & linear \\
\hline 2 & 2 & 14 & Sigmoid & - & linear \\
\hline 3 & 2 & 16 & Sigmoid & - & linear \\
\hline 4 & 2 & 18 & Sigmoid & - & linear \\
\hline 5 & 3 & $7: 9$ & Sigmoid & Sigmoid & linear \\
\hline 6 & 3 & $10: 12$ & Sigmoid & Sigmoid & linear \\
\hline 7 & 3 & $13: 15$ & Sigmoid & Sigmoid & linear \\
\hline 8 & 3 & $16: 18$ & Sigmoid & Sigmoid & linear \\
\hline
\end{tabular}

Tab. 2 Test Network Mean Square Error Mse

\begin{tabular}{|c|c|c|}
\hline $\begin{array}{c}\text { Test network } \\
\text { number }\end{array}$ & $\begin{array}{c}\text { 1000th training cycle are } \\
\text { ultimately }\end{array}$ & $\begin{array}{c}\text { the mean square error } \\
\text { (mean square error (mse) }\end{array}$ \\
\hline 1 & 0.6302 & 0.099 \\
\hline 2 & 0.5835 & 0.099 \\
\hline 3 & 0.5800 & 0.099 \\
\hline 4 & 0.4070 & 0.099 \\
\hline 5 & 1.0332 & 0.099 \\
\hline 6 & 0.1057 & 0.099 \\
\hline 7 & 0.4363 & 0.099 \\
\hline 8 & 0.0244 & 0.099 \\
\hline
\end{tabular}

The difference between the target output and the actual output of a scatter diagram is as follows:

Test net $1 \quad(\mathrm{n}=12)$

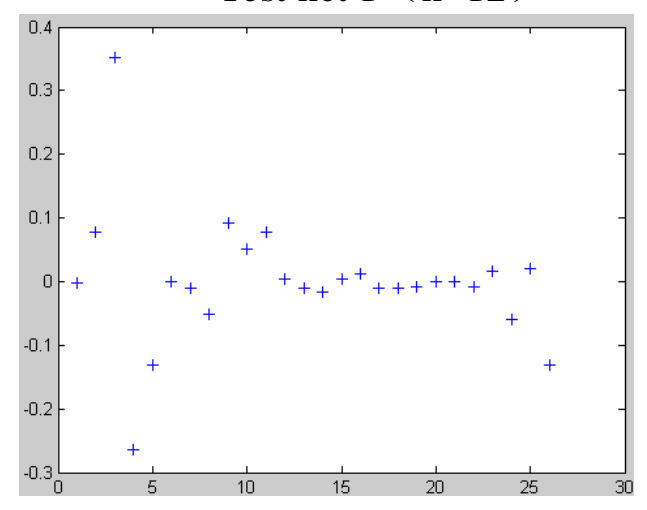

Test net 2 $(\mathrm{n}=14)$

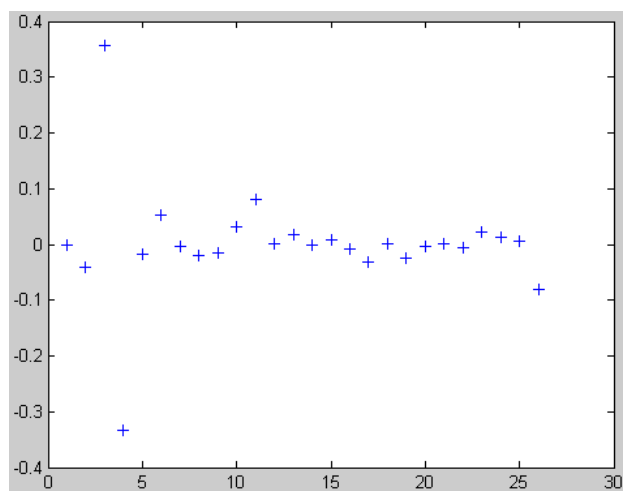


Test net $3(n=16)$

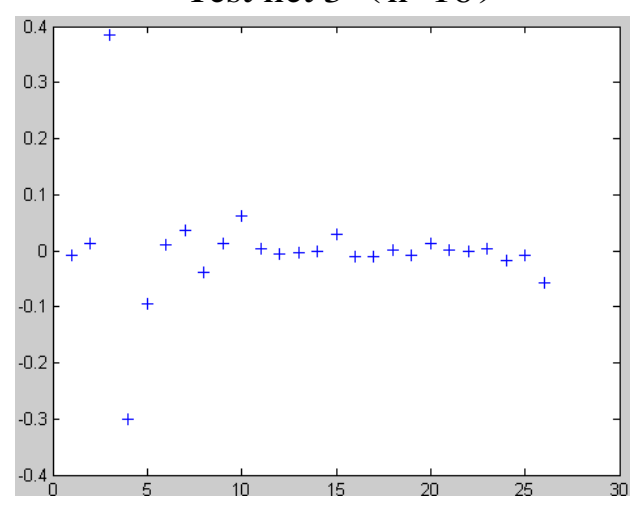

Test net $4(\mathrm{n}=18)$

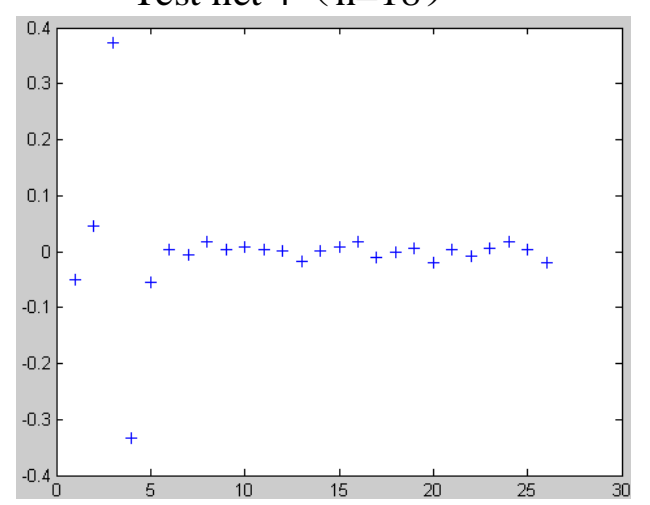

Fig.1 Scatter Plot of Error between Two Layer Test Network Target Output and the Actual Output

Test net $5(7: 9)$

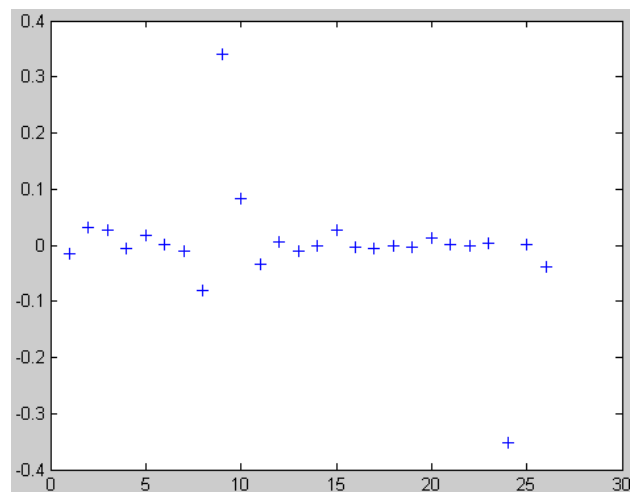

Test net $7(13: 15)$

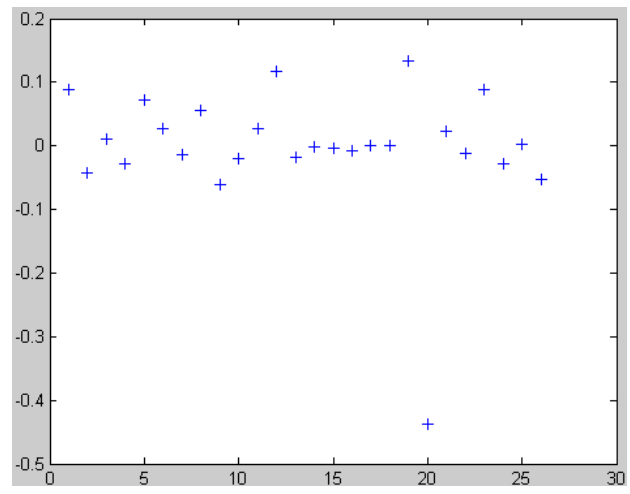

Test net $6(10: 12)$

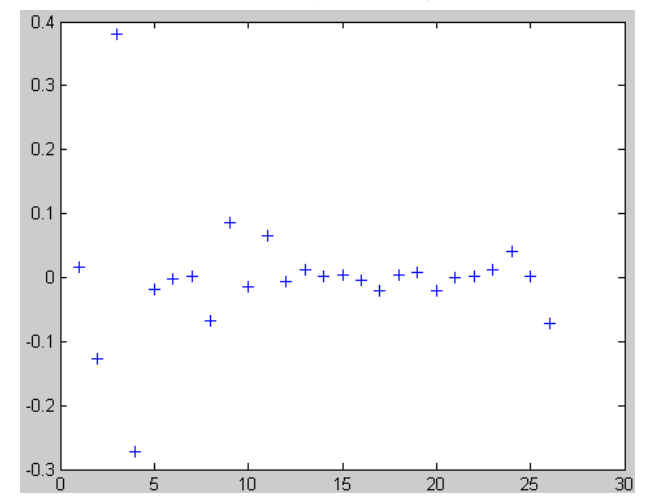

Test net $8(16: 18)$

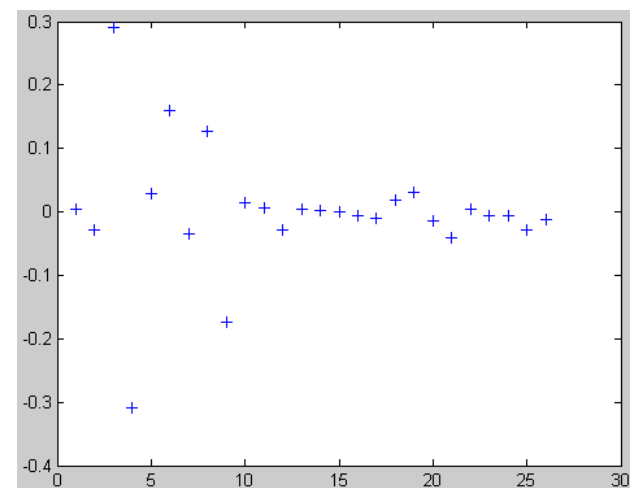

Fig. 2 Scatter Plot of Error between Three Layer Test Network Target Output and the Actual Output

It can be seen from the figure 1 and figure 2, the error value distribution between $-0.1 \sim 0.1$ as evaluation standard, the two layers of test network, only 1 test network, the error range is bigger, experiment network 2, 3 and 4 error tends to be stable, but there are two points of error change respectively. In three layers in the network test, the 5, and 6 test network and test network error range is bigger, and 7 test network error is stable, compared with the test network 2, 3 and 4 test network test network, test network 7 error is more stable, there is only one point of the error range is bigger. So the three layers BP network is chosen as the final model structure, number of hidden layer neurons values range between $13 \sim 15$. Other model parameters take a conservative way, at the cost of training. At the cost of training speed for the stability of the model, the parameters are as follows: learning rate: 0.5 expected error: 0.01 , maximum training cycle: 10000 , training function: traindm excitation function, sigmoid- sigmoid- linear function. 


\section{Model Predicted Results}

This paper uses the Matlab software operating model, and through the network was trained [13, 14], each hidden layer are finally selected contains 15 three-tier network of neurons. Training error curve was shown in figure 3.

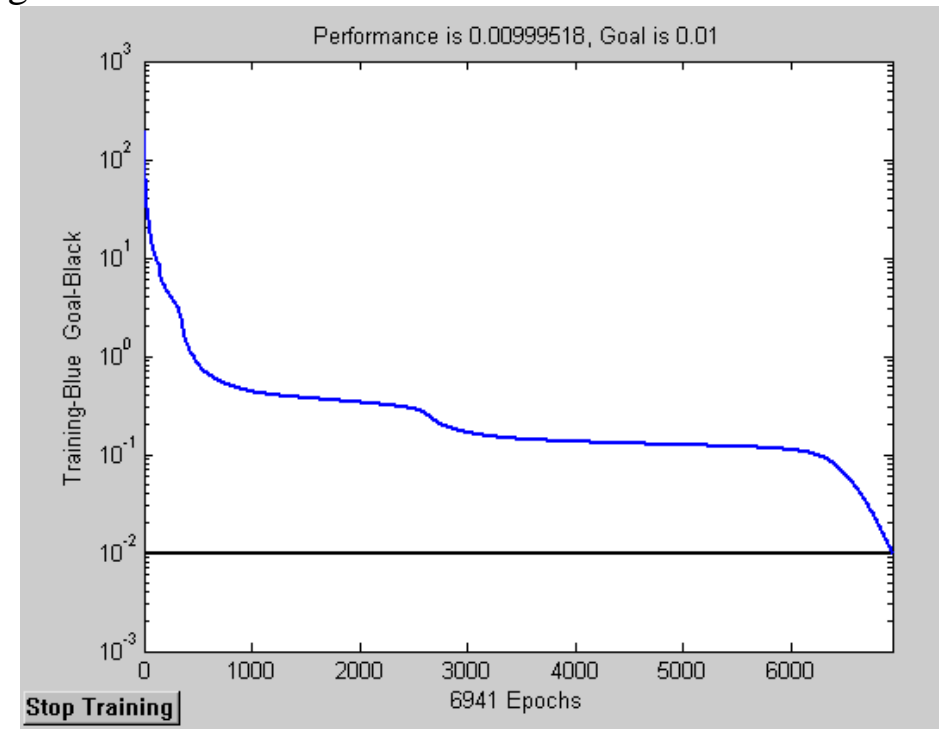

Fig. 3 Training Conditional Curve

BP neural network model has been used to predict 21201, 21301 and 2408 working face floor. According to the actual measurement and data to quantify the influence factors of floor damage depth, the result was as shown in table 4.

Combining with the measured data and computer simulation data, according to 21201, 21301 and 2408 the working face, three floor damage depth results are shown in table 5, can get the floor damage depth and the relationship between the single factor between mining depth (figure 4), and can guide damage depth prediction.

Working face are obtained by figure 4 curve relationship between length of $150 \mathrm{~m}$, the floor damage (h1) and the mining depth $(\mathrm{H})$ between the logarithmic fitting curve of the proceeds of the prediction formula: $h_{1}=6.3615 \ln (H)-26.946$

Tab. 4 Influence Factors of Quantitative Statistics of Damage Depth for 21201, 21301 and 2408 Working Face Floor

\begin{tabular}{|c|c|c|c|c|c|c|}
\hline \multirow{2}{*}{$\begin{array}{c}\text { working } \\
\text { face }\end{array}$} & $\begin{array}{c}\text { Gepth } \\
(\mathrm{m})\end{array}$ & $\begin{array}{c}\text { Dip } \\
\text { angle of } \\
\text { coal }\left({ }^{\circ}\right)\end{array}$ & $\begin{array}{c}\text { thickness } \\
(\mathrm{m})\end{array}$ & $\begin{array}{c}\text { Length of } \\
\text { working } \\
\text { face }(\mathrm{m})\end{array}$ & $\begin{array}{c}\text { Floor } \\
\text { ability to } \\
\text { resist } \\
\text { damage }\end{array}$ & $\begin{array}{c}\text { Whether } \\
\text { there is a cut } \\
\text { through fault }\end{array}$ \\
\hline 21201 & 460.20 & 6 & 2.61 & 175.00 & 0.40 & 0 \\
\hline 21301 & 616.00 & 8 & 2.70 & 149.00 & 0.50 & 0 \\
\hline 2408 & 641.55 & 8 & 2.59 & 123.50 & 0.50 & 0 \\
\hline
\end{tabular}

As a prediction of input samples, establish matrix after normalization to the BP network model, through the simulation, damage depth of 21201, 2408 and 21301 working face are $11.67 \mathrm{~m}, 13.61 \mathrm{~m}$ and $14.10 \mathrm{~m}$ respectively.

Among them, ln representatives to as the base of natural logarithms, two parameters fitting curve correlation was 0.9952 .

Worth pointing out that formula 1 is combined with Chensilou coal mining depth in less than 800 
$\mathrm{m}$, under the condition of more than $800 \mathrm{~m}$ deep, floor damage depth of law needs to be further research.

Tab. 5 Damage Depth for 21201, 21301 and 2408 Working Face Floor

\begin{tabular}{|c|c|c|c|}
\hline working face & $\begin{array}{c}\text { depth } \\
(\mathrm{m})\end{array}$ & $\begin{array}{c}\text { Damage depth of } \\
\text { working face floor }(\mathrm{m})\end{array}$ & Data resources \\
\hline 21201 & 460.20 & 12.05 & actual measurement \\
\hline 21301 & 616.00 & 14.00 & actual measurement \\
\hline 2408 & 641.60 & 14.10 & numerical modeling \\
\hline
\end{tabular}

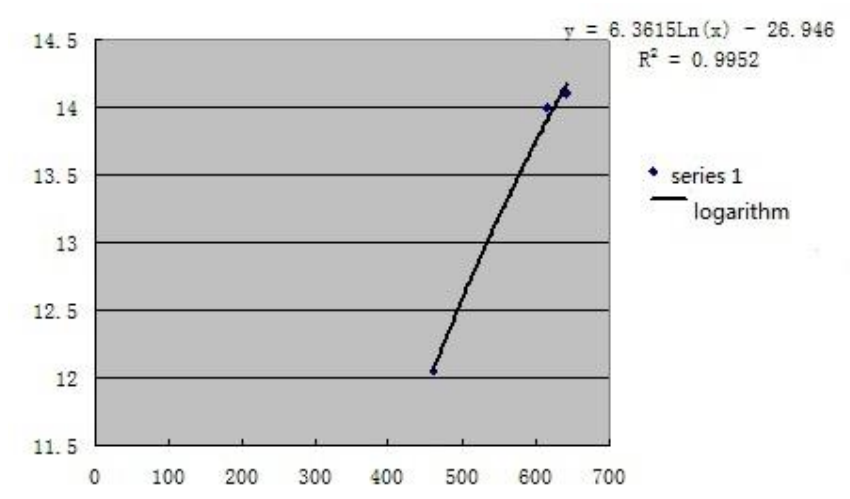

Fig. 4 Relation Curve between Floor Damage Depth and Deep

\section{Results}

Damage depth of the base based on BP neural network prediction model is established on the basis of the six main factors as follows: the mining depth, dip angle of coal seam, mining thickness and length of working face, the ability of floor to resist damage of coal floor and whether there is a cut through fault or fracture zone. The building of the BP neural network model has higher credibility to predict floor damage depth by comparison with the predicted data and measured data. Therefore, the floor damage depth prediction model provides certain reference value based on the BP neural network to establish for coal mine work safety in production

\section{References}

[1] C.X. Wang. Numerical calculation methods of inrush study [J]. Journal of coal geology and exploration, 1997, 25 (S1): 11-13.

[2] Q.Y. Feng, Chi-hui Chen. Dynamic simulation of mining of coal seam floor damage depth [J]. Journal of mine pressure and roof management, 1998 (3): 71-73.

[3] L.Q. Shi. Mining coal floor "four" division theory and the practice [J]. Journal of China university of mining, 2005, 24 (1): 16-23.

[4] B.Y. Li and S.Z. Er. Mining engineering hydrology geology [M]. Taian, shandong mining institute press, 1988: 20 to 50.

[5] Y.F. Gao, Long-qing Shi. Inrush rule with the advantage of water inrush surface [M]. Xuzhou: China university of mining press, 1999.

[6] State coal industry bureau. Buildings, water bodies and railways and main shaft and this coal pillar and press coal mining regulations [M]. Beijing: coal industry publishing house, 2000. 
[7] L.Q. Shi, Z. Lu and H. Jin etc. Mine pressure on the depth of floor damage monitoring research [J]. Journal of coal geology and exploration, 2004, 32 (6): 20-23.

[8] Z.S. Teng, F. Long, adjustable. Intelligent detection system and data fusion [J]. Beijing: mechanical industry publishing house, 2000.

[9] W. Wang. Introduction to artificial neural network and application [M]. Beijing: Beijing university of aeronautics and astronautics press, 1995.

[10] Y.W. Wang. Long distance protection layer the analog simulation research on mining overburden rock fracture [J]. Journal of coal technology, 2012 (3).

[11] W. Yan, C.L. Jiang, A.J. Wu. Base the son the line shape of multivariate regression theo ry of coal mine water inrush prediction [J]. Journal of coal technology, 2012 (3)

[12] R.Y. Zuo, X.N. Gong, H.R. Gui. Various factors under the influence of coal floor deformation damage law study [J]. Journal of northeast coal technology, 1999 (5): 3-7.

[13] B.Y. Li. Mining ore pressure and inrush research [J]. Journal of coal geology and exploration, 1986 (6): 30-36

[14] D. Jiang and J.H Wang. Based on neural network of coal floor water inrush prediction [J]. Journal of disaster science, 1999, 14 (1): 35-38. 